\title{
REFERENTIALITY OF THE PRONOUNS IT AND THAT IN COPULAR SENTENCES
}

\author{
Chiaki Kumamoto
}

\begin{abstract}
The aim of this paper is to clarify the referential status of it and that used as the subject of specificational sentences. Whether considered to be referential or non-referential, these pronouns are often treated similarly in the literature, their functional differences being hardly recognized. After a brief survey of recent literature, it will be argued that both pronouns are connected with the notion of a noun phrase involving a variable, as proposed by Nishiyama (2003), and are considered to be non-referential. It will then be suggested that a specificational sentence with $i$ as its subject assigns the value for a variable, while a specificational sentence with that as its subject confirms the identity of the value which has already been assigned.
\end{abstract}

\section{Key words}

copular sentences, cleft constructions, pronouns, referential/non-referential distinction, noun phrases involving a variable

\section{Introduction}

We shall be concerned here with the referentiality of the pronouns it and that in the types of copular sentences shown in (1) and (2).

(1) Who is the tallest girl in the class?-It/That is Molly.

(2) It/That was John that I saw.

(Mikkelsen 2005: 76)

(Hedberg 2000: 892)

These types of sentences have been classified as specificational (or sometimes equative or identificational) sentences (cf. Higgins 1979, Declerck 1988, Nishiyama 2003, Mikkelsen 2005), together with the types of sentences exemplified in (3) and (4).

(3) What John bought was a bottle of wine.

(4) The one who opened the door was John.

It will be helpful to contrast specificational sentences with other basic types of copular sentences for a clear understanding of their semantic properties. 
(5) John is a student. (Predicational)

(6) John is/that's a teacher who's been helping me with my polynomials. (Identificational)

(Higgins 1979: 244)

(7) The Evening Star is the Morning Star. /The Morning Star is the Evening Star. (Identity)

Higgins's (1979) gives the following taxonomy which shows the SubjectPredicate structure of four types of copular sentences.

$\begin{array}{lll}\text { Type } & \text { Subject } & \text { Predicate } \\ \text { Predicational } & \text { Referential } & \text { Predicational } \\ \text { Specificational } & \text { Superscriptional } & \text { Specificational } \\ \text { Identificational } & \text { Referential } & \text { Identificational } \\ \text { Identity } & \text { Referential } & \text { Referential }\end{array}$

(Higgins 1979: 264)

An important claim he makes is that the constituent in the subject position of specificational sentences is not 'Referential' but 'Superscriptional'. He considers the subject constituent to be 'Superscriptional' because it resembles the heading of a list. For example, specificational sentence (9a) can be paraphrased as (9b).
a. What I bought was a punnet of strawberries and a pint of clotted cream.
b. I bought the following things: a punnet of strawberries and a pint of clotted cream.
(Higgins 1979: 154)

The semantic function of a specificational sentence, he argues, is to assign a value for a variable: the variable is represented by the constituent in the subject position, and the value, by the constituent in the predicate position.

The view in support of the non-referential character of the subject NP of specificational sentences is elaborated by Nishiyma (2003), who proposes the notion of a noun phrase involving a variable (henceforth NPIV). An NPIV is an NP that denotes a propositional function that involves a variable [...x...]. This notion captures the semantic similarity between the subject NP of specificational sentences and a concealed question NP (cf. Baker 1968). Compare (10a) with (11).

(10) a. Mary guessed the price of eggs.

b. Mary guessed what the price of eggs was.

(11) The price of eggs was around $\$ 1.50$ a dozen. 
He contends that NP the price of eggs in either (10a) or (11) does not refer to an entity in the world but denotes the propositional function [ $\mathrm{x}$ is the price of eggs]. (11) specifies the value for the variable in the propositional function, while (10a) indicates that Mary guessed the value. The notion of NPIV will play a crucial role in our later discussion.

Although the non-referential character of the subject NP of specificational sentences seems to be irrefutable, there has been much dispute as to the characterization of the subject NP. The importance of the distinction between referential NPs and non-referential NPs has been insufficiently recognized. We shall review how the referentiality of the subject NP in specificational sentences has been treated in more recent literature, with special attention to the argument concerning the choice of pronoun in the subject position. After that, I shall show that although the pronouns it and that have commonality in that they are both non-referential, they differ in acceptability in sentences that require the so-called replacement reading of the subject NP (Fauconnier 1985, Nishiyama 2003), which reflects the different semantic functions they have.

\section{Critical review of research}

\subsection{Hedberg (2000)}

Let us first consider Hedberg's (2000) claim that the cleft pronoun and the cleft clause function referentially as a unit. She argues that the pronoun it in cleft sentences is not a meaningless, pleonastic element but a meaningful, referential element. She gives examples (12) and (13) to demonstrate that the cleft pronoun it shows parallelism not with the expletive or pleonastic it but with the propositional anaphor $i t$, which is taken to refer to a high-order discourse entity. From the fact that the pronoun it in (12c), just like that in (12d), can be replaced by demonstrative pronouns, she infers that the cleft pronoun it is referential.

a. It seems to me that you're wrong.

b. It is snowing.

c. It was John that I saw.

d. It's not true.

(13) a. *This/*that seems to me that you're wrong.

b. *This/*that is snowing.

c. This/that was John that I saw.

d. This/that's not true.

(Hedberg 2000: 892) 
Then she proposes that the cleft pronoun and the cleft clause together function in discourse as a definite description. She views definite descriptions as consisting of two parts, namely, "an indexical component which is expressed by the determiner head and determines the relation of the referent to the context, and a descriptive component, which is expressed by its nominal complement and describes the referent" (Hedberg 2000: 894). Following a theory that analyzes pronouns and determiners as allomorphs, she treats it as an intransitive form of the. To put it simply, she relates 'full' it-clefts, this-clefts and that-clefts to the $\mathrm{N}$, this $\mathrm{N}$ and that $\mathrm{N}$ respectively, and so-called 'truncated' it-clefts, this-clefts and that-clefts exemplified in (29) and (30) below to corresponding pronouns respectively. She adds that by relating clefts to definite descriptions, we can account for the identical existential and exhaustiveness conditions imposed on both.

Her discussion of the appropriate use of cleft pronouns in discourse is based on the givenness hierarchy proposed by Gundel, Hedberg and Zacharski (1993), as seen in (14). I have indicated in parentheses the cleft Hedberg relates to each pronoun and determiner for reference.

(14) the givenness hierarchy by Gundel et al. (1993)

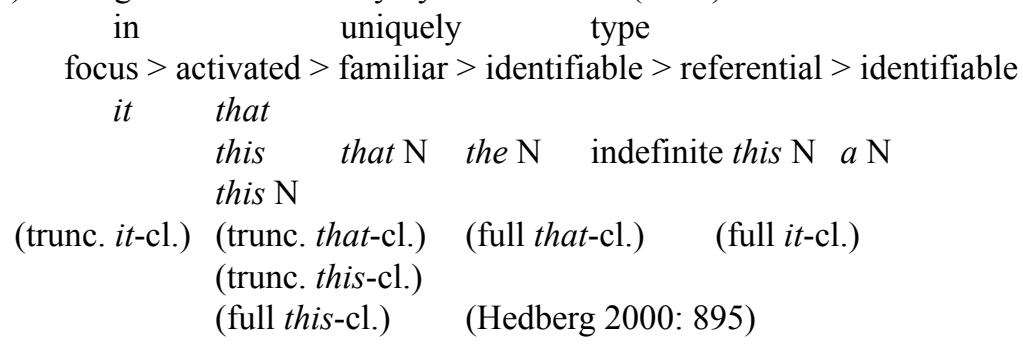

She argues that in Example (15), the cleft pronoun it is not a pleonastic one, but functions like an entity-denoting pronominal it on the givenness hierarchy which governs the selection of an appropriate referring expression.

(15) My heart beat fast, for I had thought that as the discoverer of the body I would be the first to be called; but to my surprise,

it was Marcel.

??This/that was Marcel.

??This/that was Marcel who was called.

It was Marcel who was called.

He stepped forward, neat, dark, debonair...

(Fitt, quoted in Hedberg 2000: 899) 
The reason the truncated it-cleft is selected here, she explains, is that the content of the cleft clause (that someone would be the first to be called) can be assumed to be in the addressee's focus of attention. It is possible, though not necessary, to provide the information in the form of a cleft clause in this case. She suggests that the use of this or that would be misleading here, since it would implicate focus shift to something other than 'who was called' by Grice's maxim of quantity. One problem in her argument is that she does not make clear what exactly the referent of the cleft pronoun is. Does it refer to the propositional content of the cleft clause? It could be argued that even if the pronoun is directly related to some descriptive content, it does not necessarily mean that the pronoun is referential. It would be difficult to evaluate her contention unless the notion of referentiality is clarified.

\subsection{Birner, Kaplan and Ward (2007)}

We will now turn to the discussion by Birner, Kaplan and Ward (2007), who view the demonstrative that in the subject position of equative sentences as referential. Examples (16)-(19) exemplify the three types of constructions they treat, that is, a simple equative with a demonstrative subject, an equative with epistemic would and a demonstrative subject, and what is called a th-cleft. Birner et al. argue that these constructions exhibit ambiguity depending on what the demonstrative is used to refer to. Compare (16) and (17). 'OP' here represents a contextually salient open proposition.

(16) [In coffee shop, to companion reading a newspaper]
Hey, that's Christine!
(Birner et al. 2007: 324)

(17) A: Me? I never wallow. I suffer in silence.

$B$ : No, that's Christine.

OP: 'X SUFFERS IN SILENCE'

(Birner et al. 2007: 324)

In (16), the demonstrative that has a deictic reference and the utterance is interpreted as 'That woman is Christine.' In (17), on the other hand, the demonstrative refers to the instantiation of the variable of the OP 'X SUFFERS IN SILENCE'. They point out the correspondence of B's response in (17) to the full th-cleft That's Christine who suffers in silence.

The ambiguity of the servant's response in (18) is explained as follows:

(18) [King dips his finger in a bowl held by a servant and then licks the food off his finger and proclaims it delicious.] 
King: What do you call this dish?

Servant: That would be the dog's breakfast.

OP: 'YOU CALL THIS DISH X'

(Birner et al. 2007: 329)

The demonstrative that is taken to refer either to the instantiation of the variable in the salient OP 'YOU CALL THIS DISH X' or to the salient entity evoked by the NP this dish. In the former case, the servant's utterance names the dish and can be paraphrased as 'We call this dish the dog's breakfast.' In the latter case, it provides the identity of the entity and can be paraphrased as 'That dish is the dog's breakfast.'

Similar ambiguity is observed in the th-cleft construction in (19).

A: Who's the one practicing compassionate hatred?

$B$ : That's George Bush who is practicing compassionate hatred.

OP: 'THE ONE PRACTICING COMPASSIONATE HATRED IS X'

(Birner et al. 2007: 332)

They suggest that in (19), the demonstrative can be interpreted as taking as its referent the instantiation of the variable in the OP, or the discourse entity evoked by the NP the one practicing compassionate hatred. They mention that the difference between the two interpretations is very subtle in this case. We will take up their explanation later.

The possibility of the demonstrative being used to refer to the instantiation of the variable in the OP, they claim, provides an account of the properties shared by these three constructions, namely, apparent number disagreement and apparent tense disagreement. We will give below only immediately relevant examples of simple equatives and th-clefts. In (20) and (21), the demonstrative is singular while the postcopular NP is plural.

(20) A: How I felt about you terrified me, it was so unexpected, so exciting and so dangerous.

B: Dangerous? How? Is this like what you were saying yesterday? That you have to trust that I won't hurt you?

A: No, that's my parents, I've always known that I could trust you.

OP: 'X HAS TO TRUST THAT B WON'T HURT A'

(Birner et al. 2007: 336)

(21) A: Is it true that the officials who are resigning are the President and the CEO? 


\section{B: No, that's the top three members of the Board of Directions who are resigning.}

OP: 'THE OFFICIALS WHO ARE RESIGNING ARE X'

(Birner et al. 2007: 332)

Birner et al. argue that these examples are acceptable because the demonstrative is used to refer to the instantiation of the variable in the OP, which is singular, and not to refer to the plural entity evoked in the prior discourse. In (22) and (23), we see that the main verb be is in the present tense, although the event being discussed occurs in past time.

(22) When I was 13, (that's 1969, folks) one of my older brothers came home from college with a huge stack of Marvel Comics-Thor, Avengers, Fantastic Four, etc.'

'OP: 'I WAS 13 AT TIME X'

(Birner et al. 2007: 336)

$A$ : When did you put this roof on?

$B$ : Let's see...that's 1946 that I put this roof on.

OP: 'I PUT THIS ROOF ON AT TIME X'

(Birner et al. 2007: 333)

Their explanation for this apparent tense disagreement is that in these examples the demonstrative is used to refer to the instantiation of the variable in the OP which is taking place at the time of utterance.

Their account of the three types of construction seems convincing at first sight, but it has several problems. First of all, the notion of instantiation of the variable, which is essential to their discussion, is not clearly defined. Does it represent the act of instantiation, or the result of instantiation, namely, a value, or rather, the variable itself? They claim that the demonstrative refers to the instantiation of the variable in the OP, but sometimes they say that it refers to 'the singular discourse entity' that instantiates the variable in the OP (Birner et al. 2007: 330), and other times they say that the demonstrative refers to 'the variable' (e.g. "demonstrative reference to the variable" (ibid.: 331). In the following passage, the post copular instantiation of the variable denotes 'the value in the postcopular position':

...the use of the demonstrative in combination with the equative provides a means of attaining this goal, in that the demonstrative can be used in reference to the salient variable, and then equated with the postcopular instantiation of the variable by means of the equative. (Birner et al. 2007: 340, my emphasis)

Alternative paraphrases obscure the notion of instantiation of the variable. 
Secondly, the sense in which the demonstrative that used to instantiate the variable is said to be referential is not at all clear. They state that the pronoun it and the demonstrative that in cleft constructions differ in referentiality.

Notice that while the it of an it-cleft has generally been viewed as nonreferential (but cf. Hedberg 2000 for an alternative view), the demonstrative in a th-cleft is clearly referential. (Birner et al. 2007: 332, my emphasis)

However, the it-cleft construction has also been associated with the notion of OP (cf. Prince 1986). Doesn't the pronoun it 'refer' in the same sense to the instantiation of the OP variable like the demonstrative that? They sometimes give a full $i t$-cleft or a WH-cleft as a paraphrase of a truncated that-cleft, blurring the distinction between these clefts. Furthermore, in explaining the ambiguity of the th-cleft in (19), they maintain that in this sentence, the one practicing compassionate hatred, George Bush and the demonstrative that are equated.

Since the OP equates the instantiation of the variable and the person in question, the choice between one and the other as the interpretation of the demonstrative makes very little difference in meaning. To put it another way, B's utterance in 27 (=our (19)) equates that with George Bush; since the salient OP already equates the variable and the one practising compassionate hatred, it matters very little which of these is being equated with George Bush. Thus, either choice results in the same three-way equation of the definite description, the proper name, and the demonstrative. (Birner et al. 2007: 332)

This is quite misleading because stating identity among entities and assigning the value for a variable are quite distinct notions which cannot be conflated in the notion of 'equating'. The confusion comes from their failure to understand that the NP the one practising compassionate hatred is in fact used non-referentially as the subject of a specificational sentence. This is a vital problem, but a problem too complex to be detailed here.

\subsection{Mikkelsen (2005)}

Let us now consider quite a different view maintained by Mikkelsen (2005). She claims that the subject of specificational sentences is not referential but 
rather predicative. Her argument is based on the choice of pronoun which reflects the semantic type of its antecedent. Compare (24a) and (24b).
a. The tallest girl in the class, \{that/it\}'s Molly.
b. The tallest girl in the class, $\left\{\right.$ she $/{ }^{*} i t{ }^{*}$ that $\}$ 's Swedish.

(Mikkelsen 2005: 64)

In predicational sentences like (24b), the pronoun used in the subject position is the gendered pronoun she. In specificational sentences like (24a), on the other hand, the pronoun in the subject position is either it or that, and she is not allowed. Mikkelsen takes this as evidence that the subject of specificational sentences is not referential. She also notes that it and that are used to denote properties. Cf. Examples (25) and (26).

He is a fool, although he doesn't look \{it/*him\}.

(Mikkelsen 2005: 65)

They said that Sheila was beautiful, and she is \{*it/that\}.

(Mikkelsen 2005: 93)

In some environments, however, only property-anaphoric that is allowed; she posits that the reason is not semantic but prosodic and syntactic. Her conclusion is that the subject DP of specificational sentences is property denoting, like the post-copular DP of predicational sentences. She then notices the contrast in the choice of pronoun anaphoric to the subject of copular sentences classified as identificational by Higgins (1979). Let us compare Examples (27) and (28).

That is Susan, isn't \{it/*she\}?

That woman is Susan, isn't $\{* i t / s h e\}$ ?

(Mikkelsen 2005: 121)

The pronoun must be it in (27) and she in (28). This leads her to propose a revision of Higgins's taxonomy, subsuming the type of identificational sentences exemplified by (27) under the category of specificational sentences.

As we have seen before, (27) corresponds to Hedberg's (2000) 'truncated clefts', which are viewed as having an unexpressed cleft clause. Compare the sentences in (29) and (30).
a. That's Susan.
b. That's Susan (who is knocking on the door).
c. That's Susan who is knocking on the door. 
(30)
a. It might be my best friend.
b. It might be my best friend (who had the accident).
c. It might be my best friend who had the accident.

(Mikkelsen 2005: 120)

Mikkelsen, however, contends that (29a) and (30a) need not be viewed as truncated variants of full-clefts (29c) and (30c), irrespective of their functional similarity. The similarity can be explained by assuming that the subject pronoun that or it denotes a 'property variable' in both constructions. She argues that the pronoun is bound by the cleft clause in full-clefts, while it is anaphoric to a contextually salient property in truncated clefts.

It is interesting that she recognizes the non-referential nature of the subject of specificational sentences and the involvement of a variable in the semantic content of the subject, although her notion of 'property variable' is not made sufficiently clear. Her analysis, however, is defective in that it does not distinguish the semantic function of predication from that of specification. By treating specificational sentences merely as inversions of predicational sentences, she fails to account for an important difference in the semantic function between A2 and $\mathrm{A} 4$ in the following examples.

Q: Who is the winner?

A1: The winner is JOHN.

(specificational)

A2: JOHN is the winner.

(predicational)

Q: What is John?

A3: \#The WINNER is John. (specificational)

A4: John is the WINNER. (predicational)

(Mikkelsen 2005: 160)

A2 in (31) is actually a specificational sentence, which has the function of specifying the value for the variable involved in the post-copular DP. A4 in (32), on the other hand, is a predicational sentence, whose function is to predicate the property of the referent of the subject DP. She ignores the fact that the winner in $\mathrm{A} 2$ is quite a different type of DP from the property-denoting DP in A4.

\section{Semantic functions of $i t$ and that in cleft sentences}

We have seen so far how the referentiality of the pronouns it and that in the subject position of copular sentences has been treated by a number of linguists. Whether to view the pronouns as referential or non-referential depends on how the notion of referentiality is defined. We take the view that either pronoun in the 
subject position of specificational sentences is non-referential in that it does not refer to an entity in the world. Following Nishiyama (2003), we consider that specificational sentences have the semantic structure illustrated in (33).

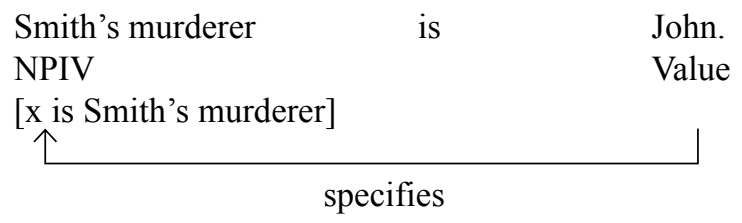

The semantic function of specificational sentences is to specify the value for the variable involved in an NPIV. By relating the pronouns it and that in the subject position of specificational sentences with NPIVs, we can reasonably explain the non-referential nature of these pronouns. Furthermore, we can satisfactorily account for the difference between it-clefts and that-clefts in the susceptibility to the so-called replacement reading by employing the notion of NPIV.

One of the advantages of the notion of NPIV is that it explains a replacement reading like the one in $(35 \mathrm{a})$.

(34) The food here is worse and worse. (Fauconnier 1985: 40)

(35) a. The food served this week is worse than the food served last week. (Replacement reading)

b. Some particular food in the cupboard is rotting away. (Transformational reading)

If the subject NP is taken to be an NPIV, (34) is interpreted as comparing different values to be assigned to the variable in the NPIV [ $\mathrm{x}$ is the food here] at different times. The replacement reading is schematically shown in (36).

(36) $\quad[\mathrm{x}$ is the food here $]$

The value for $\mathrm{x}$ is $\mathrm{A}$ at $t \quad$ The value for $\mathrm{x}$ is $\mathrm{B}$ at $t_{+1}$

$\mathrm{B}$ is worse than $\mathrm{A}$.

(cf. Nishiyama 2003)

If, on the other hand, the subject NP is taken to be a referential NP, (34) is interpreted as describing the change of the property of the referent of the food here, as in (35b). We will postulate that the replacement reading requires the subject NP to be an NPIV.

We have suggested above the possibility of taking the pronouns it and that in the subject position of specificational sentences to be cases of NPIV. However, 
there is a puzzling dissimilarity between these pronouns. Consider Examples (37) and (38).

(37) You told me that John was going out with Mary for many years. But suddenly last year, the one who John went out with was Sally.

(38) You told me that John was going out with Mary for many years. But suddenly last year, it/*that was Sally that John went out with.

Unlike the pronoun it, the pronoun that is not appropriate in any context which requires a replacement reading. The supposition that the pronoun that is incompatible with the notion of replacement of a value is further confirmed by Example (39).

(39) a. It used to be a housekeeper who cleaned my room but it is my mother now.

b. *That used to be a housekeeper who cleaned my room but that is my mother now.

While that is inappropriate in (40a), where the information about the replacement of a value is given, the pronoun is acceptable along with it and a definite NP in (40b), where the replacement of a value is not at issue.

a. Who cleaned your room?-The one who cleaned my room/It/??That used to be a housekeeper.

b. Who used to clean your room?-The one who used to clean my room/ It/That was a housekeeper.

We may add Example (41) for further confirmation.

However, when we are prepared to be guided from within, it/*that is no longer emotional desire that drives us, but the purity and clarity of reason, dictated by the 'pure will' of our hearts. (Hartmann 2011: 14)

The cleft states that the value for the variable in the propositional function [ $\mathrm{x}$ drives us] changes from 'emotional desire' to 'the purity and clarity of reason'. The pronoun originally used in this sentence is $i t$; the pronoun that is unacceptable here.

Another interesting comparison can be made between it-clefts and that-clefts in terms of scope ambiguity (cf. Example (42) below). Reeve (2012) observes 
that in it-clefts, the distributive reading of the indefinite is possible. On the widescope reading of every dog in (42), the meaning of the sentence is 'No two dogs ate the same chicken'.

(42) It was a different chicken that every dog ate. [every $>a, a>$ every] (Reeve 2012: 46)

We can conceive of every different chicken in this case, which is an indication that $i t$-clefts allow multiple value assignments. He does not include that-clefts in his discussion, but we can now contrast (42) with (43).

That was a different chicken that every dog ate.

It is clear that the wide-scope reading is not available in (43). The only possible interpretation of (43) is that there was a specific chicken that every dog ate that was different from some other chicken. We can take this as additional evidence that $i t$-clefts are compatible with the replacement of a value while that-clefts are not.

In connection with the replacement of a value, let us consider the addition of a value. We see in Examples (44) and (45) that it-clefts are compatible with the addition of a value, while that-clefts are not. To reflect Hedberg's (2000) observation on the appropriate use of full that-clefts, I have slightly changed the context in (45).

A: Bill danced with Mary.

B: No, it was Sam that danced with Mary.

C: It was also John that danced with her.

A: Do you remember who danced with Mary? Was that Bill who danced with Mary?

B: No, that was Sam that danced with Mary.

$\mathrm{C}:{ }^{*}$ That was also John that danced with her.

It is interesting to note that in the context where John did something else, a thatcleft co-occurs with also. Example (46) provides such a context.

(46) John did many kindnesses like sending me postcards. Did I tell you that a guy came to see me in the hospital? It/That was also John who came to see me in the hospital. 
The that-cleft in (46) implies the assumption given in (47b), not the one given in (47a).

a. Someone other than John came to see me in the hospital.

b. John did something other than coming to see me in the hospital.

In passing, I would like to add that the $i t$-cleft in (46) is ambiguous between the two interpretations with the different assumptions, whereas the specificational sentence with a definite NP as its subject in (48) has only the reading that assumes (47b).

(48) John did many kindnesses like sending me postcards. Did I tell you that a guy came to see me in the hospital? The one who came to see me in the hospital was also John.

We have seen so far that although both it and that in the subject position of specificational sentences are non-referential and can be related to the notion of NPIV, it-clefts and that-clefts show dissimilarity in that only it-clefts allow the replacement and addition of a value. Let us finally consider the contrast in acceptability between (49) and (50).

(49) ??That might have been Mary who won the game if the rule had not been changed.

(50) That might have been Mary.

It is clear from the foregoing that (49) cannot be interpreted in the way (51) can.

(51) It might have been Mary who won the game if the rule had not been changed.

Both (51) and (52) have the replacement interpretation given in (53), which implies that Mary might have won the game (instead of Sally) if the rule had not been changed.

(52) The one who won the game/The winner might have been Mary if the rule had not been changed. 
[ $\mathrm{x}$ won the game/ $\mathrm{x}$ is the one who won the game/x is the winner] The value for the variable might have been Mary if the rule had not been changed.

Although (50) also seems to involve a sense of replacement, it is not the same sort of replacement reading we have treated so far. A plausible context which makes the utterance of (50) appropriate will be something like the following: "The winner, Sally, is being congratulated over there. The speaker, looking at Sally, thinks that Sally might have been replaced by Mary". Notice that the subject pronoun that is not referential in (50), since we cannot paraphrase (50) as (54).

\section{??That person/She might have been Mary.}

With its subject being referential, (54) coveys the transformational reading, which is different from the intended meaning of (50) in the context.

In order to include cases like (50), we have to be careful in characterizing the differences between the pronouns. The connection of $i t$ in the subject position of specificational sentences to the notion of NPIV is fairly clear, whereas the association of that in the position with the notion of NPIV is less direct. We have seen above that the latter pronoun is not compatible with the replacement reading. The notion of variable, however, is not totally irrelevant to the semantic function of that. Example (50) shows that we are justified to assume an implicit variable, to which Sally or Mary is assigned as the value. Although we do not at the moment have sufficient evidence upon which to make a confident conclusion, I would like to suggest that the function of a specificational sentence with it as its subject is to assign the value for a variable, whereas that of a specificational sentence with that as its subject is to confirm the identity of the value which has already been assigned. Only by employing the notion of NPIV can this difference in semantic function between $i t$ and that in the subject position of specificational sentences be understood.

\section{Concluding remarks}

The question of whether simple specificational sentences with it or that as their subject should be analyzed as truncated clefts or not is an interesting one, though it is beyond the scope of this paper. Examining what governs the appropriate use of these constructions in discourse will be helpful in resolving 
this question. Furthermore, the notion of NPIV needs to be elaborated in order to explain the different aspects of value assignment to which the pronouns it and that in the subject position of specificational sentences are related. Finally, the distinction among specificational sentences, identificational sentences and identity sentences is an important issue. Taking copular sentences with the pronoun that as their subject to be specificational, for example, may blur the distinction and invite a reclassification of Higgins's taxonomy. These problems must be left to future investigation.

\section{Note}

This research was supported by a Grant-in-Aid for Scientific Research (KAKEN) (C) \#24520433. An earlier version of this paper was presented at the 33th Meeting of The Keio Semantics and Pragmatics Research Group (February 12, 2012, Keio University, Tokyo). I am grateful to Professor Gregory K. Jember for acting as a native-speaker informant and for suggesting stylistic improvements.

\section{References}

Baker, C. L. (1968) Indirect Questions in English. (Doctoral dissertation). University of Illinois.

Birner, B. J., Kaplan, J. P. and Ward, G. (2007) 'Functional compositionality and the interaction of discourse constraints.' Language 83, 317-343.

Declerck, R. (1988) Studies on Copular Sentences, Clefts and Pseudo-Clefts. Leuven: Leuven University Press.

Fauconnier, G. (1985) Mental Spaces. Cambridge, Mass.: MIT Press.

Gundel, J. K., Hedberg, N. and Zacharski, R. (1993) 'Cognitive status and the form of referring expressions in discourse.' Language 69, 274-307.

Hartmann, M. J. (2011) 'Focus, predication and specification: The case of it-clefts.' Invited Talk: CRISSP Seminar, November 28, 2011, Brussels University. http:// www.uni-tuebingen.de/en/research/forschungsschwerpunkte/collaborative-researchcenters/sfb-833/section-a-context/a7-winkler/talks.html

Hedberg, N. (2000) 'The referential status of clefts.' Language 76, 891-919.

Hedberg, N. (2012) 'Multiple focus and cleft sentences.' In: Haida, A., Veenstra, T. and Hartmann, K. (eds) The Structure of Clefts. Amsterdam: John Benjamins. http://www. sfu.ca/ hedberg/Cleft_Hedberg_NH_single_spaced.pdf

Higgins, F. R. (1979) The Pseudo-Cleft Construction in English. New York: Garland.

Mikkelsen, L. (2005) Copular Clauses: Specification, Predication, and Equation. Amsterdam: John Benjamins.

Nishiyama, Y. (2003) Nihongo Meishiku no Imiron to Goyooron (Semantics and Pragmatics of Noun Phrases in Japanese). Tokyo: Hitsuji Shoboo.

Prince, E. (1986) 'On the syntactic marking of presupposed open presuppositions.' $C L S$ 22, 208-222.

Reeve, M. (2012) Clefts and Their Relatives. Amsterdam and Philadelphia: John Benjamins. 